\title{
La extensión pedagógica en Iberoamérica como modelo de acción política: las misiones educativas laicas $^{*}$
}

\begin{abstract}
María García Alonso
Afiliada institucionalmente a la Universidad Nacional de Educación a Distancia - UNED (España). Correo electrónico: mgarciaal@fsof.uned.es. La autora es doctora en Antropología Social y Cultural por la Universidad Nacional de Educación a Distancia - UNED, (España). Entre sus publicaciones recientes se encuentran: "Miguel Soler en la tierra de los valientes. La Mina, Uruguay, 1954-1961", Revista Historia y Memoria de la Educación No. 7 (2018) y "Decisiones difíciles y sus consecuencias", en Pablo Pozzi y Paula Godinho (Comp.). Insistir Con La Esperanza El Compromiso Social y Político del Intelectual. Buenos Aires: CLACSO, 2019. Ha trabajado sobre la educación y los derechos humanos desde una perspectiva antropológica.
\end{abstract}

Recibido: 16 de enero de 2019

Aprobado: 2 de abril de 2019

Modificado: 2 de junio de 2019

Artículo de investigación científica

DOI: https://doi.org/10.15648/hc.38.2021.2819

Este artículo forma parte del proyecto "Las misiones Pedagógicas entre España y América" financiado por la Red Internacional de Estudios de Territorio y Cultura (RETEC) / Centro Internacional de Memoria y Derechos Humanos (CIEMEDH-UNED) (España).

Esta publicación está bajo una licencia Creative Commons Reconocimiento-NoComercial 4.0 (cc) BY-NC 
La extensión pedagógica en Iberoamérica como modelo de acción política: las misiones educativas laicas

\title{
Resumen
}

El artículo es una reflexión sobre un tipo especial de extensión cultural y educativa que tomó como su núcleo de actuación a las escuelas rurales: las misiones pedagógicas o culturales laicas, que fueron desarrolladas en distintos lugares de América Latina y España, especialmente entre las décadas de 1930 y 1950. Aunque en algunos momentos y países su ejecución fue compartida por las universidades, fueron desarrolladas fundamentalmente por personas e instituciones ligadas a la educación pública no universitaria, que sentían la necesidad de paliar la situación de abandono en la que se encontraba el mundo rural.

Palabras Clave: misiones culturales, misiones pedagógicas, misiones socio-pedagógicas, extensión pedagógica, extensión cultural, educación rural.

Pedagogical extension in Ibero-America as a model of political action: the lay educational missions.

\begin{abstract}
The article is a reflection on a special type of cultural and educational extension that focused on rural schools: the pedagogical or secular cultural missions. These were developed in different parts of Latin America and Spain, especially between the 1930s and 1950s. Although at some moments and in some countries their execution was shared by universities, they were developed mainly by people and institutions linked to non-university public education, who felt the need to alleviate the situation of abandonment in which the rural world was immersed.
\end{abstract}

Key words: cultural missions, pedagogical missions, socio-pedagogical missions, pedagogical extension, cultural extension, rural education.

\section{Extensão pedagógica na Ibero-América como modelo de ação política: missões educacionais laicas}

\section{Resumo}

O artigo é uma reflexão sobre um tipo especial de extensão cultural e educacional que teve como núcleo de ação as escolas rurais: as missões pedagógicas ou culturais laicas, que se desenvolveram em diferentes lugares da América Latina e da Espanha, 
especialmente entre as décadas de 1930 e 1950. Embora em alguns momentos e países sua execução fosse compartilhada pelas universidades, foram desenvolvidos fundamentalmente por pessoas e instituições vinculadas ao ensino público não universitário, que sentiram a necessidade de amenizar a situação de abandono em que se encontrava o mundo rural.

Palavras-chave: missões culturais, missões pedagógicas, missões sócio pedagógicas, extensão pedagógica, extensão cultural, educação rural.

\section{L'extension pédagogique en Ibéro-Amérique comme modèle d'action politique: les missions éducatives laïques}

\section{Résumé}

L'article est une réflexion sur un type particulier d'extension culturelle et éducative qui a pris les écoles rurales comme noyau d'action: les missions pédagogiques ou culturelles laïques ont été développées dans différents endroits en Amérique latine et en Espagne, en particulier entre les décennies 1930 et 1950. Même si leur exécution ait été partagée par les universités à certains moments et dans certains pays, ces missions ont été essentiellement développées par des personnes et des institutions liées à l'enseignement public non universitaire, qui ressentaient le besoin de pallier la situation d'abandon dans laquelle se trouvait le monde rural.

Mots clés: Missions culturelles, missions pédagogiques, missions socio-pédagogiques, extension pédagogique, extension culturelle, éducation rural.

\section{INTRODUCCIÓN}

"Atravesé en Bolivia, en época de cosecha, cerca de dos mil quilómetros; en Perú anduve algo más de ese recorrido y Ecuador lo atravesé todo. En toda esa extensión, no vi un solo arado de hierro, una sola segadora, una sola trilladora, ni siquiera una carreta o un carro. Esa es la verdad. Lo otro son palabras. Y quedan, para las gentes que más o menos queremos pensar con nuestras propias cabezas, dos soluciones posibles: o vivir bajo el mundo inconmensurable y absurdo de las palabras o vivir luchando por superarlo, el triste drama de las realidades"1.

1 Citado en la intervención de la edil Lilia Muniz en la sesión ordinaria de la Junta Departamental de Maldonado (Uruguay), el 29 de agosto de 1997, en un homenaje al maestro Julio Castro, al cumplirse 
Así reflexionaba el maestro uruguayo Julio Castro al volver a su país tras uno de los numerosos viajes que realizó por América Latina en los años cincuenta. Para él y para tantos otros, la extensión del territorio y la lejanía de los centros de poder político no debían poner barreras a la extensión de los derechos ciudadanos. Reemplazando los nombres de los países, sus palabras podrían haber sido dichas sobre muchas otras naciones del continente americano. También resultarían familiares en la España de los años treinta del pasado siglo para los misioneros pedagógicos. Uno de ellos, Miguel Hernández describiría a los niños yunteros andaluces, con sus versos tristes, como la "carne de yugo" que nace "más humillada que bella, con el cuello perseguido por el yugo para el cuello".

Hablar de lo que tantos hicieron, con los medios y las posibilidades que cada uno de ellos tenía disponible para cumplir con el deber de ser hombres y mujeres conscientes, podría llevarnos muchas páginas. Por ello trazaré aquí solo unas pocas pinceladas de lo que fue un movimiento de justicia social y educativa que se recrearía desde México a la Patagonia y que también cruzaría el océano para llegar a la Segunda República española: las misiones laicas.

Para precisar más el enfoque de mis palabras, primero debo apuntar lo que entiendo por extensión cultural o pedagógica. En mi opinión se trata de todo aquel intento organizado y sistemático de difundir el conocimiento a sectores de la población que no están incluidos en ninguna institución educativa formal, llevado a cabo por universidades, institutos normales o cualquier otra organización civil: sindicato, partido político, grupo estudiantil, etc. No se trata por tanto de un tipo de actividad que pueda circunscribirse únicamente a las universidades, aunque han sido sus actividades de difusión las más estudiadas. En general introduce, tal y como señala Paulo Freire, un factor de desigualdad en la difusión de ideas y conocimientos, ya que unos enseñan y otros aprenden ${ }^{2}$. Cuando uy/actastaq/1997/Ago2997.html\#12 (fecha de consulta: 25 de noviembre de 2018). El cuerpo ejecutado de Julio Castro se encontró el 21 de octubre de 2011.

2 Paulo Freire, ¿Extensión o comunicación? La concientización en el medio rural (México, D.F.: Siglo XXI Editores, 1973). 
vinculamos la palabra extensión con el concepto ya señalado de misión, añadimos un componente místico a esta tarea. El misionero "que extiende" debe ser un modelo moral para el que recibe su enseñanza, su labor es evangelizadora y, tal y como se creía en los primeros tiempos de la colonia con la diseminación del cristianismo, la asimilación de este conocimiento podría salvar el alma del receptor, en este caso, de los males de la incultura.

Dicho esto, estas páginas intentan hacer una reflexión con ejemplos de distintos países sobre los objetivos de algunas de las iniciativas pedagógicas llevadas a cabo por las instituciones que han tenido encomendada la educación pública, especialmente la no universitaria: los institutos normales y otros organismos que cada uno de los Estados estipuló para esta tarea. Aunque en algunos momentos y países la intención de estas experiencias pueda coincidir con las de sindicatos y partidos políticos y ser compartidas en su ejecución por las universidades, mi interés se enfoca en el contenido y las formas de la extensión cultural y educativa que toman como su núcleo de actuación a las escuelas, especialmente las escuelas rurales. Esta actuación es considerada "de extensión" cuando se dirige a un público no escolarizado, a pesar de que sean las escuelas los lugares elegidos para servir de centro difusor de conceptos y prácticas. Construir un gallinero o hacer una obra de teatro para la comunidad no son actividades incluidas en el currículum académico, aunque a través de ellas se difundan ideas sobre lo que debe ser un ciudadano y su papel en la construcción del futuro colectivo.

El Estado en la práctica social (no en su definición filosófica o política) se encarna en un conjunto de autoridades públicas de distinto ámbito territorial. Funciona siempre a partir de la interpretación del poder que hacen los funcionarios encargados de ejercerlo en un entramado de instituciones interrelacionadas pero no siempre alineadas. Su dominio no es por tanto coherente y unidireccional, sino a menudo descentralizado y magmático. Si la soberanía popular delega en todos los ciudadanos una parcela del poder estatal, su cara visible son los empleados públicos que serán, a fin de cuentas, quienes realicen las actividades educativas a las que me voy a referir. La extensión magisterial, que no se opone sino que complementa los proyectos educativos de otros colectivos, es una 
actividad que tiene un fuerte vínculo institucional con el Estado, incluso cuando no sea consciente de esta relación. Existe para garantizar precisamente los derechos de ciudadanía de las clases populares que no tienen acceso a una formación de calidad, a menudo enfrentándose a gobiernos que no tienen interés en tratar a todos sus naturales como miembros legítimos de la nación. Y lo hacen utilizando la escuela pública como un dispositivo amplificador de experiencias y de distribución de recursos materiales y simbólicos que sirve para canalizar iniciativas de transformación social. Ya sea por el empuje de estudiantes magisteriales, de maestros profesionales o de otras estructuras generadas por las autoridades educativas del Estado, la conformación de los centros educativos como "territorios de extensión" convierte las decisiones de individuos o colectivos en proyectos civilizatorios, en colaboración o en manifiesta oposición a los establecidos desde un gobierno central. De hecho, en muchas memorias y testimonios es palpable la tensión entre los proyectos de país de las capitales y los de las regiones periféricas, más alejadas de los núcleos de decisión y más cerca del campo que se quiere transformar.

Estas fricciones se producían de modo más acusado en aquellos territorios donde el enfrentamiento entre la Iglesia y el Estado obligaba a los destinatarios últimos de la formación a tomar partido entre un ideario religioso y otro de carácter laico, que quería desterrar la religión de los programas educativos y a los sacerdotes de las aulas. La elección de la palabra misionero para difundir una educación ciudadana no cristiana suponía un desafío explícito a las instituciones religiosas, cuyos fieles se vieron atacados llegando incluso a tomar las armas para la defensa de su fe como lo harían los cristeros en México o los carlistas y otros grupos político-religiosos en España.

Es bastante frecuente, por ejemplo, en el caso de las misiones culturales mexicanas de los años treinta, encontrar telegramas agónicos que le piden al Presidente de la República Lázaro Cárdenas armamento para defenderse tras algún asesinato de misioneros, o textos que informan

214 del enorme rechazo de las poblaciones católicas a su labor laicista, tal y como relata el director de la misión a Ixtlán de Juárez en Oaxaca (1932): 
"Con motivo de la Semana Santa y tomando en consideración que los vecinos necesitaban una demostración contraria a sus prácticas, no se suspendieron las labores, a pesar de que los maestros así lo solicitaron a la Dirección Federal de Educación. Por el contrario, la Mesa Directiva de la Sociedad de Maestros giró una circular a los maestros y maestras que acudieron a las fiestas religiosas, pidiéndoles que se abstuvieran de realizar esos actos, ya que con los mismos se obstruccionaba la obra de la Misión y se fomentaba el fanatismo de los vecinos, negando así una de las aspiraciones de nuestro movimiento social.

Esto dio lugar a que en una reunión especial, y en presencia de todos los maestros y miembros de la Misión, se tratara el siguiente punto: El fanatismo religioso y la influencia clerical son los principales obstáculos que han impedido el avance rápido del país. Durante la Semana Santa se logró que los vecinos trabajaran tres días. [...]

Puñal en mano y al grito de que los misioneros eran enemigos de la "religión", un vecino en estado de ebriedad, estuvo a punto de asesinar al profesor de Cultura Física, Ramón B. Miranda, quien logró defenderse con éxito, gracias a su serenidad y a los conocimientos de lucha que posee. Con este motivo los ánimos se exaltaron"3.

En este texto se hará especial énfasis en aquellos movimientos que desarrollaron de modo más acusado esta característica de laicidad: el modelo mexicano y el español, planteando en la última parte sus influencias posteriores en varias experiencias latinoamericanas, especialmente evidentes en Uruguay, Argentina y Cuba, aunque algunas de sus estrategias culturales sirvieran como ejemplo a iniciativas semejantes en otros países y contextos en los que la disputa entre Iglesia y Estado no se producía de modo explícito.

\section{LAS EXTENSIONES PEDAGÓgICO-CULTURALES NORMALISTAS Y EL FENÓMENO MISIONERO}

Como diría Lunacharski en una entrevista que concedió a Rodolfo Llopis en 1930, todo proceso revolucionario -y tanto en América Latina como

3 Secretaría de Educación Pública, Las Misiones Culturales, 1932-1933 (México: Talleres Gráficos de la Nación, 1933), 190-192. 
en Europa hubo varios en el convulso siglo XX-buscaba "apoderarse del alma de los niños"4 y la competencia por llevarse ese precioso don de futuro era feroz. Se necesitaban muchos maestros para alimentar esas almas de ideas nuevas y para convencer a sus padres de que el tiempo de los de abajo había llegado. La óptica con la que se miraban los problemas sociales tras las revoluciones cambió drástica y violentamente, apareciendo en el escenario político actores y dilemas que ni siquiera habían sido planteados anteriormente. La transformación de los derechos y deberes ciudadanos obligaba a explicar la naturaleza de los cambios que se pretendían a poblaciones que ni siquiera se encontraban en los mapas de las patrias burguesas. Esto fue especialmente apremiante en aquellas zonas rurales que se encontraban al margen de todas las decisiones que les afectaban, en manos de caciques, abandonados por unos gobernantes que los habían excluido de todos los planes educativos, como diría en 1928, en una junta de directores de escuelas normales rurales, el responsable de las misiones culturales de México Rafael Ramírez:

"Las escuelas normales no incluyeron entre sus finalidades la preparación de los maestros rurales, porque no se dieron cuenta de que en nuestro país existía planteado el problema rural. Si lo hubieran conocido, tal vez habrían intentado algo para atacarlo y resolverlo. Yo nunca oí antes de la revolución hablar de este problema. Yo nunca escuché una sola palabra acerca de la necesidad de incorporar a los campesinos y a los indígenas al progreso general del país. Esta preocupación vino con la revolución y se ha acentuado en estos últimos años de gobierno. Fue entonces cuando comprendimos que una buena parte de la población de la República vive sustraída a todo influjo civilizador, al grado de que es una verdadera tontería pensar que está sumada a nosotros formando una nacionalidad. Este trabajo de integración de los núcleos sociales está confiado a esas modestas escuelas que se han diseminado en el país y que se ha confiado a los llamados maestros rurales. [...] Estos maestros

4 Rodolfo Llopis, "Pedagogía soviética. Hablando con Lunacharski", Boletín de la Institución Libre de Enseñanza, año LIV, No. 837 (1930): 19. Entre las obras del intelectual ruso sobre la educación popular destaca Las artes plásticas y la política en la Rusia revolucionaria (Barcelona: Seix Barral, 1969). 
han sido reclutados entre las personas de buena voluntad que medianamente sabe leer y escribir, porque no ha sido posible recurrir al contingente de maestros que año tras año están dando las escuelas normales fundadas en las capitales de los Estados. Las autoridades escolares se muestran relativamente satisfechas de que las cosas vayan pasando así, porque en los contados casos en que las escuelas rurales se han puesto en manos de doctos profesores normalistas, se han encerrado dentro de las cuatro paredes de su escuela y se han olvidado de que alrededor del plantel hay un vecindario por integrar" 5 .

La cultura y la educación diseñada para el pueblo debían adquirir movilidad y extensión. Movilidad porque la urgencia, la lejanía de las ruinosas escuelas rurales y la poca instrucción de los futuros encargados de diseminar la justicia social obligaba a la concentración de los maestros y a la itinerancia de los encargados de formarles. Extensión porque debía llegar a todas partes donde fuera posible expandir los tentáculos de los Estados. Las distancias eran enormes, los caminos tortuosos, las instalaciones precarias, el hambre y la pobreza generalizadas. Solo generando un nuevo tipo de vínculo emocional con las comunidades y llenando de misticismo la tarea civilizadora era posible conseguir la abnegación y la resiliencia suficiente para abrirse paso en medio de tantas dificultades.

A partir de la Revolución Francesa y de modo conscientemente planeado a partir de la toma del poder por los soviets en Rusia, el discurso político y cultural internacional empezó a impregnarse con palabras que habían sido antes empleadas en un contexto religioso. No hay que olvidar que Lunacharski pensaba también -como lo haría Benjamín- que la religión era la única fuerza capaz de despertar el entusiasmo en las gentes y "sin entusiasmo el hombre no es capaz de crear nada grande". Las frases que durante siglos habían servido para extender la fe entre los infieles empezaron a ser utilizadas con unos significados inéditos. La acción de difundir el pensamiento revolucionario se denominó propaganda (al estilo

5 "Conferencia de Rafael Ramírez en la Junta de Directores de las Escuelas Normales Rurales" (1928), en Archivo General de la Nación, México (AGNM), fondo Secretaría de Educación Pública, Dirección de Misiones Culturales, caja 38. 
de la Propaganda fide); a la imposición de cualquier ideología a aquellos que todavía no la poseían, adoctrinamiento ${ }^{6}$. El trasvase terminológico fue filtrándose incluso en la palabra misión, que comenzó a ser entendida como un vehículo para llevar las ideas políticas más radicales a los lugares más apartados Más allá del empeño de unas personas concretas que se desplazaban por las aldeas en campañas de alfabetización o de reforma agraria, la palabra misión comenzó a formar parte constitutiva de cualquier ser humano contemporáneo. Tal y como diría el filósofo español José Ortega y Gasset, "la idea de misión es, pues, un ingrediente constitutivo de la condición humana, y como antes decía, sin hombre no hay misión, podemos ahora añadir: sin misión no hay hombre"7.

La conversión de todo hombre moderno en un misionero, de todo Estado en servidor y propagador de alguna idea, coincide con una transformación simbólica que despoja a las iglesias del monopolio de la emoción institucionalizada -aquella que conmovía los espíritus con sentimientos místicos- para fomentar un tipo de emoción laica, que fortalecía los vínculos afectivos de los ciudadanos de los Gobiernos revolucionarios con las estructuras que consolidaban su poder. Así, las escuelas se transformaron en templos, los intelectuales y artistas en profetas que agitaban las conciencias para despertar el ansia por el conocimiento. En palabras de Daniel Cosío Villegas:

"La educación no se entendió ya como una educación para la clase media urbana, sino en la forma única que en México puede entenderse: como una misión religiosa, apostólica, que se lanza y va a todos los rincones del país, llevando la buena nueva de que México se levanta del letargo, se yergue y camina. Entonces sí que hubo ambiente evangélico para enseñar a leer y a escribir al prójimo; entonces sí que se sentía, en el pecho, y en el corazón de cada mexicano, que la acción educativa era tan apremiante y tan cristiana, como dar de beber al sediento o de comer

6 Véase María García Alonso, "La emoción de la cultura. El uso político de la emoción como transformadora de espacios culturales", en Territorio e Cultura. Inclusao e exclusao nas dinamicas socioespaciais, coords. Geralda de Almeida y Beatriz Nates Cruz (Goiania y Manizales: Universidade Federal de Goias / Universidad de Caldas, 2008), 55-63.

7 José Ortega y Gasset, La misión del bibliotecario (Madrid: Ediciones Austral, 1935), $210-211$. 
al hambriento. [...] Entonces se tenía fe en el libro de calidad perenne; y los libros se imprimieron a millares y a millares se obsequiaron. Fundar una biblioteca en un pueblo pequeño y apartado parecía tener tanta significación como levantar una iglesia y poner en su cúpula brillantes mosaicos, que anunciaran al caminante lejano la existencia de un hogar donde descansar y protegerse" 8 .

Sería México el primer país iberoamericano en diseñar una política activa de integración de su población rural, y para ello la Secretaría de Educación Pública emplearía de modo institucional las estrategias de la extensión pedagógica a través de las llamadas misiones culturales, creadas en 1923 por iniciativa de José Vasconcelos.

La propia situación social de cada país, la ideología de sus líderes políticos y las necesidades prácticas de la vida cotidiana fueron trazando sustanciales diferencias en los caminos de estas misiones laicas en los diferentes países. Más allá de un posible sustrato ideológico, la diversidad étnica de las poblaciones marcó una divergencia en el estilo y en los objetivos de las distintas misiones laicas que seguirán en Iberoamérica la estela de las misiones mexicanas. España creará en 1931 un tipo de extensión educativa particular, más centrada en despertar de los sentidos a las emociones culturales que en la lucha contra el analfabetismo. Todas las experiencias posteriores recibieron en mayor o menor medida la inspiración de los dos modelos. Argentina y Uruguay, con población más homogénea, desarrollarán iniciativas afines al movimiento misionero español. También lo hará así Colombia, que había conformado su identidad nacional al margen de las adscripciones étnicas amerindias y afrocolombianas. Por su parte, Guatemala, Venezuela, Ecuador, Brasil o Panamá seguirán más de cerca los pasos comenzados en México. La Cuba revolucionaria llevaría a cabo en los años sesenta un modelo híbrido, que adaptaría elementos soviéticos, mexicanos y españoles.

8 Daniel Cosío Villegas, "La crisis de México", Cuadernos Americanos No. 32 (1947): 39. Alicia Civera Cerecedo en su texto "La trayectoria de las Escuelas Normales Rurales: algunas huellas para estudiar": 2-3, apunta que las escuelas "nacieron envueltas dentro de la mística de ser instituciones de campesinos comprometidos con la civilización y el mejoramiento de la vida de los propios campesinos". Consultable en http://snte.org.mx/seccion56/assets/218266543.pdf. (fecha de consulta: 2 de diciembre de 2018). 


\section{MÉXico: LAS Misiones CUlturales}

\section{Imagen No. 1}

Decoración del teatro al aire libre construido por los misioneros culturales en San Francisco de las Blancas, Nuevo León (México) en 1932

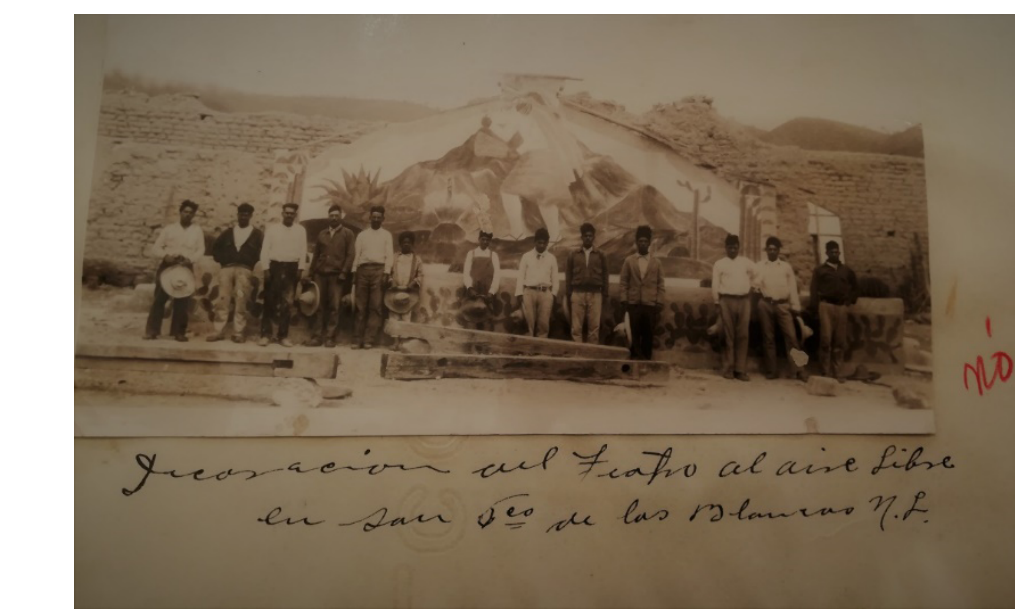

Fuente: Fondo de la Secretaría de Educación Pública. Sección Dirección de Misiones Culturales. Archivo General de la Nación, México

Podría decirse que la historia de México desde su independencia en 1810 hasta la presidencia de Lázaro Cárdenas en 1934 fue una revolución constante. Invasiones extranjeras, usurpaciones territoriales, guerras entre los partidarios de un modo religioso de ver el mundo y los que consideraban que la Iglesia católica era la fuente de todos los males, luchas fraticidas entre conservadores y liberales fracturaban la nación y las conciencias. Las idas y venidas de los distintos Gobiernos se iban sucediendo mientras los pueblos indígenas convivían con ellos a duras penas, sin conocer el español, siendo despreciados o ensalzados pero siempre desconocidos para un país que les ignoraba. 68 lenguas y 364 variantes dialectales complicaban la comunicación y aislaban a los distintos grupos étnicos. Su alma, como la de los niños rusos, había de ser conquistada y modelada para convertirla en la auténtica alma mítica del pueblo mexicano, que nada parecía tener que ver con las costumbres supersticiosas de un montón de pobres hambrientos, con sus casas de adobe y paja. Pero antes, o mejor dicho a la vez, había que encontrar los elementos mínimos para permitir la convivencia y garantizar su supervivencia, para que compartieran como ciudadanos el derecho a la tierra y a la libertad que habían sido las consignas de la Revolución. 
Esa voluntad fue explícita en el primer congreso de maestros, realizado en 1922, que tomó como lema La tierra como fuente suprema de bienestar económico y moral. Su pretensión era poner el foco en las masas campesinas para que fueran consideradas un problema social.

"Era evidente, por la euforia que invadía al país, que Vasconcelos había logrado, como dijera más tarde, «ligar el esfuerzo misionero católico, que engendró nuestra nacionalidad, con un proselitismo regenerador, que sin perjuicio de especializarse en los aspectos técnicos de la cultura moderna, lograse frutos de espíritu tan fecundos como los antiguos, cuya raíz es el amor al semejante». La verdadera misión era 'conseguir para la vida rural, un ambiente de mayor comodidad y de mayor progreso""

Si los frailes venidos durante el período colonial de la muy católica España habían conseguido transformar a través de la religión el modo de vida tradicional amerindio, los nuevos misioneros lo harían por medio de la cultura.

"A falta de un maestro completo como el fraile que sabía cultivar un campo, aserrar y ensamblar una mesa, nosotros empezamos a mandar grupos de maestros: uno de artesanías que enseñar a labrar la tierra y forjar el hierro; otro que fuera artista y pudiera inspirar a la población el gusto por la belleza, único camino que le queda al laico para acercarse a las cosas de Dios, y otro más para que incitara a la acción social y a la colaboración en la obra patriótica; otro finalmente para las primeras letras y las matemáticas. Y nació así el misionero de tipo moderno"10.

Con esta estructura mínima, grupos de maestros ambulantes comenzaron a transitar a partir de 1923 los caminos de una patria en la que el $66 \%$ de los mayores de diez años eran analfabetos. Podría decirse, como afirmaba Lunacharski refiriéndose a los campesinos en la época

9 Augusto Santiago Sierra, Las misiones culturales (1923-1973) (México D. F.: SepSetentas, 1973), 13.

10 Reflexión de José Vasconcelos (1928) publicada en sus Obras Completas y citada en Luz Elena Galván, Los maestros y la educación pública en México (México D. F.: Centro de Investigaciones y Estudios Superiores en Antropología Social, 1985), 94. 
zarista, que "su ignorancia había sido cuidadosamente cultivada"11. De ahí que el calificativo cultural pudiera tener varias acepciones aplicado a las actividades misioneras mexicanas. La primera, la que tiene que ver con el cultivo, del que deriva inicialmente la palabra. Se trataba de aprender a cultivar la tierra y las mentes de un modo inédito en las aisladas poblaciones. Trabajo y conocimiento deberían darse la mano. La segunda, la que se enlaza estrechamente con los modos de vida y con la comprensión del mundo. En esos primeros años de los encuentros entre los misioneros y sus "pueblos de misión" la percepción de la realidad política y social de ambos, de sus intereses y sus deseos era difícilmente compartible, en gran parte de los casos por una imagen distorsionada que era mutua. El Gobierno enviaba lejos a aquellos hombres y mujeres para enseñar las reglas del juego de la cultura dominante y, con ello, permitía jugar a los dominados.

Los misioneros eran un puente entre lo viejo y lo nuevo, la revolución y la tradición. Su labor se repartía entre la formación acelerada de maestros rurales, concentrados durante veintiún días en los llamados institutos sociales, y la mejora de las condiciones materiales y culturales de las comunidades. Para ello los alumnos y los vecinos serían formados en aquellas pequeñas labores de las que pudieran sacar un rendimiento económico que les ayudara a sobrellevar su dura vida, se construirían escuelas y parques infantiles, se darían cursos de higiene y puericultura, se enseñarían danzas y cantos, se inventarían nuevas recetas de cocina con los alimentos más comunes, se aprendería a decorar un hogar moderno. En 1928, cuando el cinematógrafo daba sus primeros pasos, ya era usado en apoyo de las explicaciones y las conferencias. El archivo de la Dirección de Misiones Culturales está lleno de reclamos de aparatos de radio y de los transformadores que permitían abrir esa ventana de la ciudad al campo, difíciles de obtener y de mantener con una energía eléctrica precaria. Pronto se incorporaría al equipo misionero un operador de cine que tendría entre sus funciones la de "imprimir fotografías y cintas cinematográficas sobre los aspectos más interesantes de la vida de las comunidades, bellezas

11 Rodolfo Llopis, "Pedagogía soviética. Hablando con Lunatcharski": 18. 
naturales de la región y trabajo de la misión"12. Se irían incorporando progresivamente las bibliotecas, los títeres, el teatro y el adorno mural de las escuelas. También en el campo el muralismo se convertiría en la seña de identidad del México posrevolucionario.

Cuando la población estaba en sintonía con los intereses de los misioneros su llegada era recibida con gran regocijo, como un regalo del Gobierno que había que agradecer y devolver con largueza. Véase como ejemplo el tono de esta carta enviada en 1926 a la Dirección de las Misiones, desde el mismo Estado de Oaxaca que seis años más tarde plantearía, como ya vimos al principio de este texto, tantos problemas a la acción misionera, problemas que ya se intuían en este escrito.

"Me es grato informar a usted que el recibimiento que nos han hecho en esta villa es el más suntuoso de todos los que nos han dispensado en Oaxaca. El primer pueblo que está al pie de la Sierra, Santo Domingo, nos recibió con arcos triunfales. En ese lugar nos dieron el primer banquete. En Santa Catarina, donde pasamos la noche, la música tocó durante toda ella, y con esto y los cohetes fue imposible dormir. Al siguiente pueblo al otro día le rodeamos un poco, pero no fue posible. Nos dieron alcance y nos llevaron a comer. No habíamos terminado y ya estaban las autoridades de San Mateo, quienes se empeñaron en llevarnos a su pueblo y no nos dejaron continuar nuestro camino ese día. Por la noche dimos una veladita, dándoles una conferencia. Debo decir que, tanto esta como las anteriores fue traducida al zapoteco, por alguno que no faltó contestando los indios en este mismo idioma. [...] Las autoridades de cada pueblo se fueron agregando y pudimos llegar a Yalalag con las de los pueblos referidos. A la entrada de la población nos esperaba primero el Ayuntamiento, luego seguía una formación de los 54 pueblos del Distrito de Villa Alta. Después las escuelas, luego los maestros de este instituto ${ }^{13}$, y por último particulares. Cinco arcos triunfales se habían levantado. Fue necesario dar tres discursos en el camino de la entrada, en la plaza y por último dar otra conferencia que se tradujo al zapoteco párrafo por párrafo por uno de los maestros más

12 Augusto Santiago Sierra, Las misiones culturales (1923-1973): 38.

13 Como vimos, el instituto era el encuentro formativo con los maestros. 
inteligentes del grupo. [...] Es la primera vez que tengo que decir tres discursos y dar dos conferencias en 12 horas. Sigue el entusiasmo por las misiones, y junto con él he sentido que hay personas a quienes no les agrada y nos hacen política. No hay remedio" ${ }^{14}$.

En la dilatada trayectoria que han tenido en el tiempo y en el espacio las misiones culturales estas percepciones e intereses se fueron transformando debido sobre todo a la reflexión que realizaron los propios participantes sobre su tarea, a las ideologías de los distintos períodos presidenciales y a la evolución de las guerras internas que polarizarían a los campesinos. Las guerras cristeras determinaron que las misiones se concentraran en aquellas zonas del país donde hacía falta contrarrestar los mensajes de la Iglesia en armas con el fin de realizar una "campaña de pacificación espiritual".

En los años treinta las misiones culturales fueron integradas como parte de las actividades de las escuelas normales regionales. Estas últimas no preparaban para el magisterio nacional sino que, como su nombre indica, estaban restringidas en su orientación a la formación específica de los maestros que debían insertarse en una realidad cultural y social específica de cada región.

La voluntad explícita de cumplir ese mandato quedó plasmada en el articulado de las Bases que señalan la organización, el plan de estudio y el funcionamiento de las escuelas normales rurales, que tendrían como una de sus funciones prioritarias "la incorporación de las pequeñas comunidades de la misma región al progreso general del país, mediante los trabajos de extensión educativa que al efecto estas instituciones realicen". El capítulo IV del documento especificaba cómo debía trabajarse en esta incorporación. En las comunidades se establecerían "cursos nocturnos o vespertinos, sabatinos y dominicales, de desanalfabetización, divulgación científica, de agricultura y pequeñas industrias, de economía doméstica, etc. Estos cursos serán sistemáticos y en ellos tomarán parte activa como maestros los alumnos de la Escuela de los grados

14 "Carta dirigida por Javier H. Uranga, Jefe de la Misión Cultural en Oaxaca, a Rafael Ramírez, Director de las Misiones Culturales en México" (28 de octubre de 1926), en AGNM, fondo Secretaría de Educación Pública, Dirección de Misiones Culturales, caja 6. 
avanzados". Las clases en los locales comunitarios serían complementadas por otros cursos "vespertinos o nocturnos para adultos, destinados a los vecinos de la comunidad en la que la institución funciona. En estos cursos se aprovecharán también como maestros a los alumnos de la Escuela Normal rural en los cursos avanzados. [...] Los trabajos de extensión de los alumnos normalistas quedarán sujetos a la supervisión de los profesores de la institución"15.

Estas actividades de extensión educativa y de mejoramiento social tendrían, en palabras de Rafael Ramírez,

"un doble propósito. Primero, saldar con el vecindario la deuda contraída [con la comunidad que acoge a la institución], contribuyendo así ellas mismas a acelerar el progreso de la nación; y segundo, enseñar prácticamente a los futuros maestros cómo se trabaja por la incorporación de las pequeñas comunidades de indígenas y campesinos, entrenándolos en el manejo de los diversos métodos indispensables para un buen trabajo social. Una escuela normal rural que no realice esta finalidad, no es un verdadero centro de formación de maestros"16.

La presidencia de Lázaro Cárdenas explícitamente convertirá esa actividad en un instrumento de propaganda de las ideas socialistas:

"La educación que imparta el Estado será socialista, y, además de excluir toda doctrina religiosa, combatirá el fanatismo y los prejuicios, para lo cual, la escuela organizará sus enseñanzas y actividades de forma que permita crear en la juventud un concepto racional y exacto del universo y de la vida social"'17.

En años posteriores las comunidades indígenas irían poco a poco reivindicando sus propios derechos culturales ${ }^{18}$, mostrando que es posible

15 "Bases que señalan la organización, el plan de estudio y el funcionamiento de las escuelas normales rurales" (1927), en AGNM, fondo Secretaría de Educación Pública, Dirección de Misiones Culturales, caja 21.

16 "Conferencia de Rafael Ramírez en la Junta de Directores de las Escuelas Normales Rurales" (1928), en AGNM, fondo Secretaría de Educación Pública, Dirección de Misiones Culturales, caja 38.

17 Citado en Augusto Santiago Sierra, Las misiones culturales (1923-1973), 48.

18 Para el análisis más detallado del "problema indígena” y su relación con las misiones culturales, véase 
alcanzar la ciudadanía sin renunciar a la tradición, adaptando y transformando aquello que aprendieron de los misioneros. En el presente todavía perdura esta actividad convertida fundamentalmente en un tipo especial de educación de adultos ${ }^{19}$.

\section{EsPAÑA: LAS MISIONES PEDAGÓGICAS}

\section{Imagen No. 2}

Niños viendo el cine por primera vez en la Misión Pedagógica a las Alpujarras, Granada, España

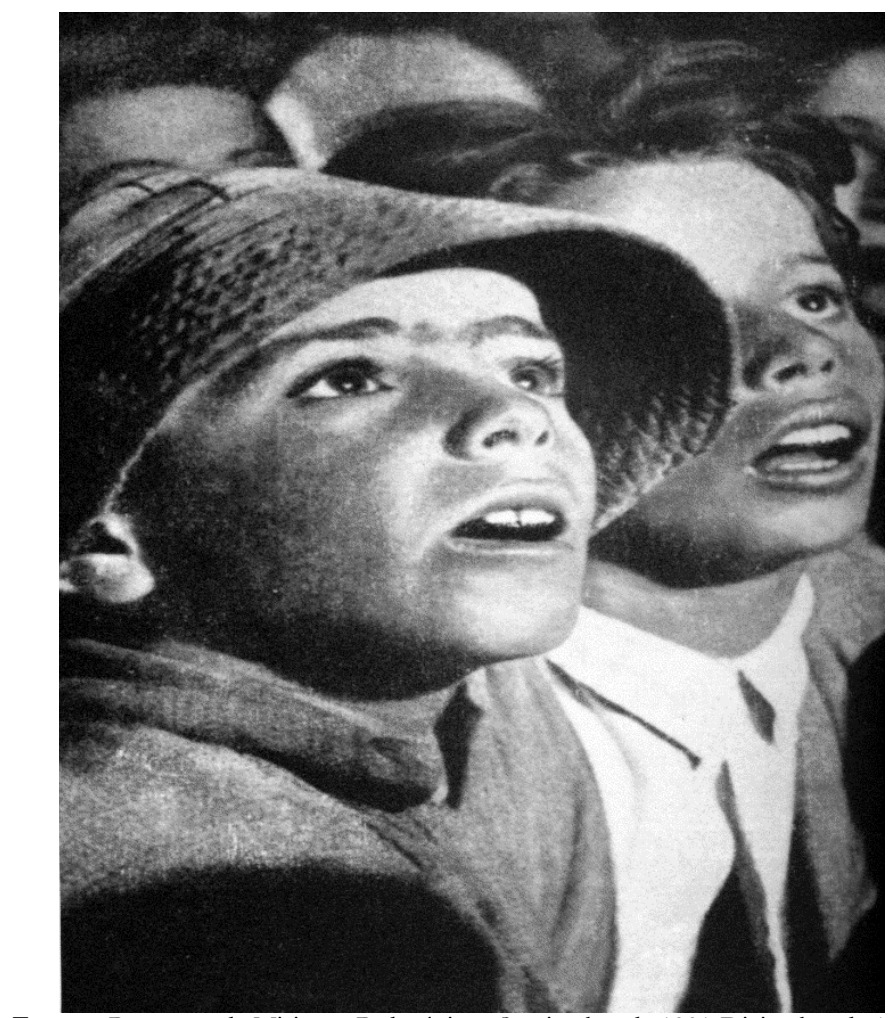

Fuente: Patronato de Misiones Pedagógicas. Septiembre de 1931-Diciembre de 1933 Madrid: Museo Pedagógico Nacional, 1934

El 14 de abril de 1931, tras unas elecciones municipales que dieron la victoria a los partidos republicanos, comienza en España un período breve, intenso y fértil que acabaría con el golpe de Estado del General

Marco A. Calderón Mólgora, Educación rural, experimentos sociales y Estado en México: 1910-1933 (Zamora, Michoacán y México D.F.: El Colegio de Michoacán y Fideicomiso Teixidor, 2018).

19 Hughes, Lloyd H., Las misiones culturales mexicanas y su programa (París: UNESCO, 1951). 
Francisco Franco en julio de 1936. La Segunda República supuso una oportunidad de transformación social, un momento de honda reflexión sobre la responsabilidad de los intelectuales como agentes activos en la formación de una nueva conciencia ciudadana. Como había ocurrido en México, esta revolución sin sangre solo podía mantenerse mediante un cambio educativo que fue acometido desde el primer instante. Las misiones pedagógicas españolas se inauguraron en mayo del 31, un mes después de estrenado el nuevo sistema de gobierno.

La relación entre la iniciativa mexicana y la española es evidente. El conocimiento que se tenía en España de sus características puede rastrearse al menos hasta la Exposición Iberoamericana de Sevilla en 1929, cuando el Gobierno de México mostrará al mundo sus proyectos educativos. Para este acontecimiento se preparó una gran obra profusamente ilustrada: Las Misiones Culturales en 1927: las escuelas normales rurales (1928), que seguramente sería conocida por los pedagogos del círculo de la Institución Libre de Enseñanza, siempre muy pendientes de las innovaciones internacionales en el ámbito de la educación. ${ }^{20}$ Esta inspiración indudable no se tradujo en un trasvase de principios y modus operandi, porque ni en sus fines ni en su ejecución siguieron el mismo procedimiento.

El adjetivo pedagógicas aplicado a las misiones laicas había sido utilizado por Joaquín Costa y Francisco Giner de los Ríos en 1899. En esa misma época se emplea para denominar a las delegaciones de docentes europeos o estadounidenses -algunos de ellos pertenecientes a órdenes religiosas- que se trasladan a países de América Latina para impulsar la creación de escuelas profesionales y la promoción de nuevos métodos de enseñanza. Manuel B. Cossío no dudó en utilizarla cuando impulsó la creación de las misiones, a pesar de que su utilización confundía su planteamiento general hasta tal punto que se vio obligado a aclararlo en la introducción de la primera de las memorias del Patronato que las tenía a su cargo. Estas misiones no serán unas escuelas ambulantes ni están llamadas a suplir la labor de los maestros rurales. Se reclamaban como

20 Las Misiones Culturales en 1927: las escuelas normales rurales (México: Publicaciones de la Secretaría de Educación Pública, 1928). Por distintos motivos esta Exposición, que debía haberse celebrado en 1927, se retrasó dos años. Esto hizo que el libro que el Gobierno mexicano había preparado para presentar su proyecto educativo tenga esa fecha. 
voluntariamente "antipedagógicas", con un "carácter antiprofesional de comunicación de cultura exclusivamente espontánea y difusa"21. Sin embargo, tal y como ocurriera en el caso mexicano, su lugar predominante de acción sería la escuela rural. A ella llegarían las conferencias, el cine, los gramófonos, los títeres, los coros, las bibliotecas, el Teatro y el Museo del Pueblo y los cursos de perfeccionamiento docente ${ }^{22}$.

Pocos misioneros eran contratados para estas tareas. En su mayoría formaban un grupo heterogéneo de voluntarios - estudiantes de magisterio, inspectores de primera enseñanza, docentes y profesionales de distintas ramas del saber- que pretendían sobre todo divertir a su público y sacarlo del tedio de sus días. Por ello eran recibidos a veces como feriantes antes de saber que habían sido enviados por el Gobierno de la República. Su relación obvia con la escuela y su también obvio programa de festejos, que incluían para maravilla de los asistentes la iluminación de las plazas con un generador eléctrico, llenaba de desconcierto a aquellas gentes que veían el cine o los cuadros de Goya por primera vez. También recibían la enemistad o el boicot de los sectores más cercanos a la Iglesia católica, que hasta la República tenía el control mayoritario de la educación de los españoles.

También aquellos maestros itinerantes tenían primero que buscar un espacio de inteligibilidad que era difícil de obtener, incluso si tenemos en cuenta que los misioneros y los pueblos visitados compartían la misma lengua y similares tradiciones. Como se puede leer en la memoria de la misión a Navas de Madroño, en Cáceres:

"Es de notar el género de ignorancia en que se hallan estos pueblos. Es una ignorancia distinta de la que un observador ingenuo pudiera creer. No se trata de ignorancia de verdades particulares, de falta de noticias, de estar enterados al día de acontecimientos más o menos recientes; es algo distinto. Lo que ellos ignoran es toda esa serie de supuestos de nuestra cultura, los cimientos que sustentan y hacen posible nuestro

21 Patronato de Misiones Pedagógicas. Septiembre de 1931-Diciembre de 1933 (Madrid: Museo Pedagógico Nacional, 1934), XIII.

22 Para más información sobre las Misiones Pedagógicas españolas, véase Eugenio Otero Urtaza y María García Alonso (eds.), Las Misiones Pedagógicas, 1931-1936 (Madrid: SECC, 2006) y Alejandro Tiana Ferrer, Las Misiones Pedagógicas. Educación popular en la Segunda República (Madrid: Los Libros de la Catarata, 2016). 
saber. Por eso la primera y más angustiosa impresión que de ellos se recibe es que falta el terreno común para entenderse; que no hay, intelectualmente, convicciones comunes de donde partir" ${ }^{23}$.

En las numerosas fotografías sacadas por los misioneros de los vecinos de esas aldeas olvidadas, se ven los rostros asombrados por la profunda impresión que, sobre su vida sensible, tenía el arte cuyo disfrute era, por primera vez, gratuito. Era difícil, no obstante, sostener la utilidad práctica de este proyecto. No estaba dirigido a la propaganda política, ni luchaba contra el analfabetismo; ni siquiera se quedaban el tiempo suficiente para formar a los maestros rurales en las técnicas de la fabricación de un guiñol. Cuando se marchaban quedaban las bibliotecas; y la música de los discos de pizarra podía escucharse una y otra vez mientras las agujas de los gramófonos lo permitieran. Y habían visto a mujeres jóvenes solas, sin maridos ni amos, hablar por sí mismas del nuevo derecho de las mujeres al voto. Y en el cine, Charlot mostraba sin rubor, públicamente, los apasionados besos a sus novias de celuloide, unos besos que hicieron exclamar a la vecina de un pueblo de Segovia: "eso sí es progreso", según contaba a su nuera la misionera Amparo de Zulueta.

El carácter antipedagógico de la pedagogía misionera duró lo que la República: poco más de ocho años, tres de ellos de guerra. Incluso durante este corto tiempo sobrevivió a duras penas pues algunos gobiernos consideraron que eran una pérdida de dinero y esfuerzo. Al igual que había sucedido en la presidencia de Lázaro Cárdenas, las misiones durante el conflicto armado se convirtieron en un instrumento propagandístico para la defensa de los valores republicanos. En la Exposición Universal de París de 1937 las imágenes misioneras acompañaron al Guernica de Picasso, y las filmaciones sobre su actividad se marcharon del país buscando nuevos públicos. A excepción de Estampas 1932, el resto de la producción cinematográfica de las misiones no ha podido hallarse. Durante cuarenta años desaparecieron los besos de las películas de Chaplin para las españolas y los españoles. Y la experiencia de las misiones se marchó al exilio.

23 Patronato de Misiones Pedagógicas. Septiembre de 1931-Diciembre de 1933, 37. 


\section{Herencias misioneras y nUeVas creaciones}

La dispersión de los misioneros pedagógicos por América Latina, con las Memorias del Patronato de Misiones en la maleta, difundió el experimento español especialmente por el Cono Sur, que había conocido muy de cerca a aquel excepcional embajador de la cultura que era Federico García Lorca. Lorca había desarrollado un proyecto de extensión teatral propio: La Barraca, que coincidía en sus fines con el Teatro del Pueblo de Alejandro Casona, aunque era de carácter más profesional. En el viaje del poeta a Argentina en 1933 enseñó el arte de los títeres a un joven Javier Villafañe. Años más tarde, en 1935, Villafañe empezará a recorrer el país con su espectáculo de marionetas ${ }^{24}$.

En 1941 el escritor español Alejandro Casona publicó en Buenos Aires Una misión pedagógico-social en Sanabria. Teatro estudiantil, reeditando la memoria de esta experiencia de 1934, que en el original aparecía sin firma por ser parte del proyecto colectivo de las Misiones republicanas $^{25}$. El impacto de esta publicación fue enorme no solo por resultar accesible al público argentino y uruguayo, muy receptivos a esta tarea, sino también por poner el foco en el carácter transformador que tuvo esa misión en la vida de la comarca de Sanabria. Sería la más "mexicana" de las misiones españolas y fue esta simbiosis la que inspiró iniciativas semejantes. En 1942 el Consejo de Educación de Córdoba comenzó su propia versión de las Misiones Pedagógicas. La ciudad de Buenos Aires tampoco sería ajena a este movimiento, inaugurando en estos años el Camión-Cine. El estilo artístico de estas propuestas se acomodaba bien al modelo de difusión cultural español, puesto que en Argentina las diferencias étnicas nacían de la llegada masiva de inmigrantes de distintas partes del mundo que en el siglo XX, a diferencia de México, presentaba una escasa presencia relativa de población autóctona.

24 Véase Pablo Medina, "Apuntes para una historia de las Misiones Pedagógicas en Argentina”, en Cine educativo y científico en España, Argentina y Uruguay, eds. Alicia Alted y Susana Sel (Madrid: Ramón Areces, 2016), 76-88.

25 Alejandro Casona, Una misión pedagógico-social en Sanabria. Teatro estudiantil (Buenos Aires: Publicaciones del Patronato Hispano Argentino de Cultura, Colección Cuadernos de Cultura Española, 1941). 
En Rosario, la Escuela Experimental de Olga y Leticia Cossetini comenzó a realizar también "misiones de divulgación cultural" urbanas. Su Escuela fue acompañada ocasionalmente por los poetas Nicolás Guillén, Gabriela Mistral (que había colaborado también en las misiones culturales de Vasconcelos), Rafael Alberti, Juan Ramón Jiménez y Zenobia Camprubí, así como por otros intelectuales españoles en el exilio. Las actuaciones tenían lugar en las plazas de una barriada de la $\operatorname{ciudad}^{26}$.

Otros países de América hicieron sus propios ensayos misioneros en la década de los treinta y cuarenta, en pugna o colaboración con las emergentes políticas indigenistas. En algún caso, como el de Ecuador, con un Estado central fraccionado, convivieron políticas regeneracionistas -que intentan crear una homogeneidad cultural fomentando valores patrióticos entre una población india que consideraba pasiva y atrasada- y misiones higiénicas, centradas en el control de plagas, y pensadas como "un sistema de bienestar móvil", que abriría el camino a otras organizaciones de carácter comunitario ${ }^{27}$.

En Colombia el Gobierno de López Pumarejo (1934-1938), en la conciencia de que para integrar a su población rural había que hacer del país una inmensa escuela, ensayó entre los años 1934 y 1936 su Campaña de Cultura Aldeana:

"El propósito fundamental de la campaña fue la transformación de la vida rural de Colombia y pretendía instaurar una nueva manera de sentir, pensar y actuar en el pueblo, para acercarlo a los principios de la higiene y la estética que imponía el período. [...] [En palabras del Ministro de Educación Luis de Mesa la aldea] ha sido hasta ahora un miembro muerto del organismo nacional, gangrenado por la miseria y

26 Sobre la labor pedagógica de las hermanas Cossettini véanse Ovide Menin, "El ensayo de «escuela serena» realizado por las hermanas Cossettini en la República Argentina", Revista da Faculdade de Educaçâo (São Paulo) 24: 1 (1998): 160-176 y María del Carmen Fernández y Ariel Alejandro Soto, "El teatro de títeres en la Escuela Serena. Rosario, Provincia de Santa Fe, Argentina (1935- 1950)", History of Education in Latin America 1 (2018): 1-14.

27 Un interesante estudio sobre la educación en Ecuador y las misiones sociales (o misiones de protección campesina) se encuentra en Mercedes Prieto, Liberalismo y temor: imaginando los sujetos indígenas en el Ecuador postcolonial, 1895-1950 (Quito: FLACSO-Abya Yala, 2004). 
el aburrimiento, hay que convertirla en el pueblecillo limpio, de calles y habitaciones a donde llegue el sol, y con el sol la alegría, y con la alegría el amor a la vida y al trabajo, a un trabajo libre y prometedor" 28 .

La aventura misionera uruguaya ${ }^{29}$ nació en 1945 por la iniciativa de los estudiantes de magisterio de la capital y de algunos de sus profesores, y se fue extendiendo por otros núcleos del país en los años siguientes (hasta que la dictadura militar acabó con ella). Los misioneros normalistas - entre los que se encontraba también un estudiante de medicina que actuó de practicante-, llevaron a Caraguatá, un rancherío de Tacuarembó, el cine, la música del violín de Moisés Lasca, los títeres, un cargamento de poemas y relatos que repartir en ranchos donde faltaba la comida y el agua. Allí se encontraron con una realidad que no esperaban: que antes de educar y de distraer era necesario dar de comer, de vestir, combatir el frío y limpiar la miseria de los ranchos.

Las consecuencias de aquel viaje fueron muy hondas tanto para sus protagonistas como para la historia de la educación uruguaya. Los misioneros se convirtieron en la vanguardia de una corriente de pensamiento pedagógico que no quiso ser cómplice de una situación de desigualdad social y que intentó poner los medios para paliarla. Por ello, las siguientes misiones cambiarían su adjetivo pedagógicas por el de socio-pedagógicas pues, sin abandonar las herramientas culturales que permitían fomentar la sensibilidad artística allí donde era prácticamente imposible disfrutarla -así como provocar la risa, uno de los más preciados bienes de todo ser humano-, tratarían también de mejorar algunas condiciones materiales que permitieran dignificar la vida en los rancheríos. Así lo hicieron durante más de veinte años y así lo hacen también en el presente, después de una larga interrupción que impusieron la historia y las condiciones sociales.

28 Carlos Jilmar Díaz, El Pueblo: de sujeto dado a sujeto político por construir. El caso de la Campaña de Cultura Aldeana en Colombia (1934-1936) (Bogotá: Fundación Francisca Radke, Universidad Pedagógica Nacional, 2005), 100, 102.

29 Véase María García Alonso y Gabriel Scagliola (eds.), Misiones Socio-pedagógicas de Uruguay (19451971). Documentos para la memoria (Montevideo: Administración Nacional de Educación Pública-ANEP, 2012). 
En 1949 también se establecieron en Guatemala "misiones de cultura ambulantes" 30 , que intentaban la modernización de las costumbres como parte de ese proceso de conversión de indios en campesinos, general en América, y cuya actividad terminó también con el golpe de Estado de 1954.

En Cuba, siguiendo aquella máxima que une revolución política y educativa, el castrismo invirtió un gran esfuerzo ideológico y humano para que su versión de lo que era la cultura -coincidente en parte con la idea mantenida en la España de los años treinta, pero con el matiz de adoctrinamiento que es intrínseco a un Estado comunista- llegara a todos los confines de la isla. La escolarización se universalizó; el teatro y el cine se acercaron a un público inédito.

\section{Imagen No. 3}

Exhibición de una película de Charlot en Baracoa, Cuba.

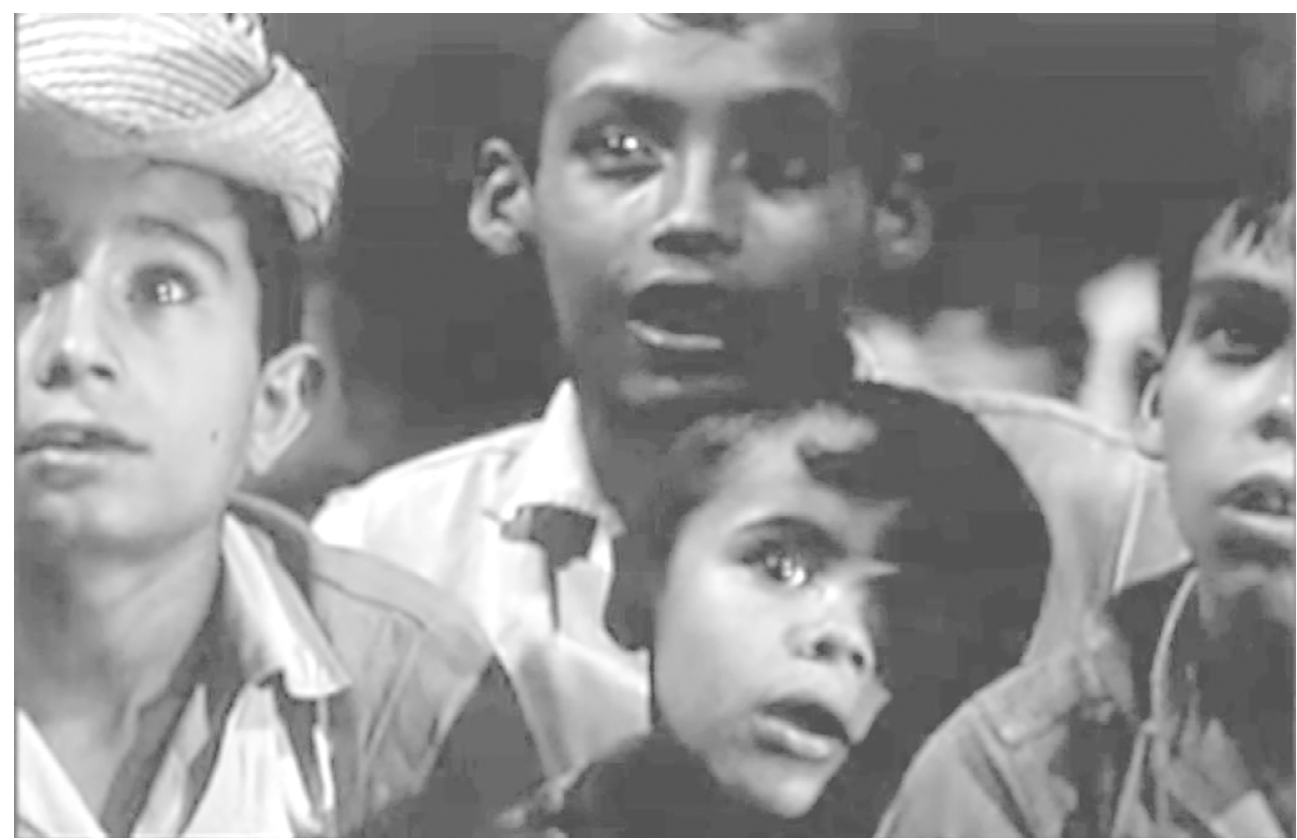

Fuente: Fotograma de la película Por primera vez, de Octavio Cortázar (1967).

$30 \quad$ Véase Meike Heckt, "Educación intercultural liberadora para todos en Guatemala: una posibilidad para el futuro de una sociedad multilingüe y pluriétnica", en Textos Ak'Kutan No. 25 (Cobán: Centro Bartolomé de las Casas, 2003). 


\section{Bibliografía}

\section{Fuentes primarias}

\section{Archivo}

Archivo General de la Nación (AGNM). México. Fondo Secretaría de Educación Pública, Dirección de Misiones Culturales.

\section{Memorias}

Las Misiones Culturales en 1927: las escuelas normales rurales. México: Publicaciones de la Secretaría de Educación Pública, 1928.

Secretaría de Educación Pública. Las Misiones Culturales, 1932-1933.

México: Talleres Gráficos de la Nación, 1933.

Patronato de Misiones Pedagógicas. Septiembre de 1931-Diciembre de 1933. Madrid: Museo Pedagógico Nacional, 1934.

Casona, Alejandro. Una misión pedagógico-social en Sanabria. Teatro estudiantil. Buenos Aires: Publicaciones del Patronato Hispano Argentino de Cultura, Colección Cuadernos de Cultura Española, 1941.

\section{Otros}

Llopis, Rodolfo. "Pedagogía soviética. Hablando con Lunatcharski". Boletín de la Institución Libre de Enseñanza, año LIV, No. 837 (1930): 18-24.

Lunacharski, Anatoli V. "La revolución y el arte”. En la obra del mismo autor Las artes plásticas y la política en la Rusia revolucionaria. Barcelona: Seix Barral, 1969.

Ortega y Gasset, José. La misión del bibliotecario. Madrid: Austral, 1935.

\section{Fuentes secundarias}

Calderón Mólgora, Marco A. Educación rural, experimentos sociales y Estado en México: 1910-1933. Zamora, Michoacán y México D.F.: El Colegio de Michoacán y Fideicomiso Teixidor, 2018.

Civera Cereceda, Alicia. "La trayectoria de las Escuelas Normales Rurales: algunas huellas para estudiar". Consultable en http://snte. org.mx/seccion56/assets/218266543.pdf. (fecha de consulta: 2 de diciembre de 2018). 
Cosío Villegas, Daniel. "La crisis de México". Cuadernos Americanos No. 32 (1947): 29-51.

Díaz, Carlos Jilmar. El Pueblo: de sujeto dado a sujeto político por construir. El caso de la Campaña de Cultura Aldeana en Colombia (1934-1936). Bogotá: Fundación Francisca Radke, Universidad Pedagógica Nacional, 2005.

Fernández, María del Carmen y Ariel Alejandro Soto. "El teatro de títeres en la Escuela Serena. Rosario, Provincia de Santa Fe, Argentina (1935-1950)". History of Education in Latin America 1 (2018): 1-14.

Freire, Paulo. ¿Extensión o comunicación? La concientización en el medio rural. México, D.F.: Siglo XXI Editores, 1973.

Galván, Luz Elena. Los maestros y la educación pública en México. México D. F.: Centro de Investigaciones y Estudios Superiores en Antropología Social, 1985.

García Alonso, María. "La emoción de la cultura. El uso político de la emoción como transformadora de espacios culturales". En Territorio e Cultura. Inclusao e exclusao nas dinamicas socioespaciais, coordinado por Geralda de Almeida y Beatriz Nates Cruz. Goiania y Manizales: Universidade Federal de Goias / Universidad de Caldas, 2008, 55-63.

García Alonso, María y Gabriel Scagliola (eds.). Misiones Socio-pedagógicas de Uruguay (1945-1971). Documentos para la memoria. Montevideo: Administración Nacional de Educación Pública-ANEP, 2012.

Heckt, Meike. "Educación intercultural liberadora para todos en Guatemala: una posibilidad para el futuro de una sociedad multilingüe y pluriétnica”. En Textos Ak'Kutan No. 25. Cobán (Guatemala): Ak> Kutan, Centro Bartolomé de las Casas, 2003.

Hughes, Lloyd H. Las misiones culturales mexicanas y su programa. París: UNESCO, 1951.

Medina, Pablo. "Apuntes para una historia de las Misiones Pedagógicas en Argentina". En Cine educativo y científico en España, Argentina y Uruguay, editado por Alicia Alted y Susana Sel. Madrid: Ramón Areces, 2016, 76-88. 
Menin, Ovide. "El ensayo de «escuela serena» realizado por las hermanas Cossettini en la República Argentina". Revista da Faculdade de Educaçâo (São Paulo) 24: 1(1998): 160-176.

Muniz, Lilia. Homenaje al maestro Julio Castro en la sesión ordinaria de la Junta Departamental de Maldonado (Uruguay), el 29 de agosto de 1997. Intervención completa en http://www.juntamaldonado. gub.uy/actastaq/1997/Ago2997.html\#12.

Otero Urtaza, Eugenio y María García Alonso (eds.). Las Misiones Pedagógicas, 1931-1936. Madrid: SECC, 2006.

Prieto, Mercedes. Liberalismo y temor: imaginando los sujetos indígenas en el Ecuador postcolonial, 1895-1950. Quito: FLACSO-Abya Yala, 2004.

Sierra, Augusto Santiago. Las misiones culturales (1923-1973). México D. F.: SepSetentas, 1973.

Tiana Ferrer, Alejandro. Las Misiones Pedagógicas. Educación popular en la Segunda República. Madrid: Los Libros de la Catarata, 2016.

Para citar este artículo: García Alonso, María. "La extensión pedagógica en Iberoamérica como modelo de acción política: las misiones educativas laicas", Historia Caribe Vol. XVI No. 38 (EneroJunio 2021): 209-236. DOI: https://doi.org/10.15648/hc.38.2021.2819 